Check for updates

Cite this: RSC Adv., 2019, 9, 1084

Received 12th November 2018 Accepted 13th December 2018

DOI: $10.1039 / \mathrm{c} 8 \mathrm{ra09337g}$

rsc.li/rsc-advances

\section{Kinetics, equilibrium, statistical surface modeling and cost analysis of paraquat removal from aqueous solution using carbonated jujube seed $\uparrow$}

\begin{abstract}
Mohamed Zbair, (iD *a Zakaria Anfar, (iD b Hassan Ait Ahsaine iD ${ }^{b}$ and Hamza Khallok ${ }^{\mathrm{c}}$
This paper reports the removal of paraquat from an aqueous solution using prepared carbonated jujube seed (JS/ HSO-700). JS/HSO-700 was characterized by XPS, TGA, FTIR, $N_{2}$ physisorption, SEM, and Raman techniques. FTIR revealed the presence of active species on the JS/HSO-700 surface. The removal rate of paraquat was investigated as a function of multiple operational factors such as contact time, adsorbent dose and solution $\mathrm{pH}$. Adsorption mechanism was fully investigated based on FTIR, Raman, and BET analyses before and after adsorption. Response surface methodology modeling using central composite design was performed to statistically optimize the adsorption conditions. The experimental paraquat removal efficiency was found to be $96.7 \pm 2.02 \%$, whereas the predicted value of the model was $94.31 \pm 4.43 \%$, showing that the predicted model values are in good agreement with the experimental value. Finally, cost analysis was performed to confirm the cost of the adsorbent based on energy consumption and reagent costs.
\end{abstract}

\section{Introduction}

Currently, due to industrial development, majority of the soil contaminants originate from industrial wastewater containing organic matter and minerals, some of which are toxic; these contaminants are released in the form of solutions, suspensions, emulsions (polar molecules) or dispersions (colloids). They are mainly composed of suspended solids, oxidizable organic matter, inorganic salts, detergents, inhibitors, acids and bases, toxins, and colorants. In most cases, their composition directly depends on the type of industry from which they are released. Paraquat is one of the widely used herbicides and presents many serious health problems. It is known as Gramoxone, which is a toxic compound. The use of this compound may create potential environmental hazards to humans and animals if exposed by ingestion, skin contact, or splash to eyes. ${ }^{1}$ It is very toxic if ingested orally in the range from 4 to $40 \mathrm{mg} \mathrm{kg}^{-1}{ }^{2}$ Still, up to $3.5 \mathrm{mg} \mathrm{kg}^{-1}$ does not cause remarkable damage to the skin or respiratory system; irreversible human lung damage is one of the biggest threats of this herbicide. ${ }^{3}$ Moreover, it is rapidly distributed in most tissues with the highest concentration found in lungs and kidneys. ${ }^{4}$ The extent of intoxication caused by paraquat

${ }^{a}$ Laboratory of Catalysis and Corrosion of Materials, Chouaïb Doukkali University, Faculty of Sciences El Jadida, BP. 20, El Jadida 24000, Morocco. E-mail: zbair. mohamed@gmail.com; Tel: +358465232839

${ }^{b}$ Materials and Environment Laboratory, Ibn Zohr University, Faculty of Sciences, Agadir, Morocco

'Team of Energy, Materials and Environment, Chemistry Department, Chouaib Doukkali University, Faculty of Sciences El Jadida, BP. 20, El Jadida 24000, Morocco $\dagger$ Electronic supplementary information (ESI) available. See DOI: $10.1039 / \mathrm{c} 8 \mathrm{ra09337g}$ depends on many factors and circumstances such as duration of exposure, the route, the amount, and the state of health of the person at the time of the exposure.

Furthermore, when paraquat enters the soil environment, it is quickly and strongly bound to clay minerals and organic matter and becomes biologically inactive. ${ }^{5}$ The danger of pollution by paraquat is increased by its high water solubility $\left(620 \mathrm{~g} \mathrm{~L}^{-1}\right){ }^{6}$ having been identified in surface and drinking waters. ${ }^{7}$ For European criteria, the maximum allowed concentrations for individual pesticides in drinking water including paraquat are $0.1 \mu \mathrm{g} \mathrm{L}{ }^{-1}$ and 1-3 $\mu \mathrm{g} \mathrm{L}^{-1}$ for surface water. ${ }^{8}$ Consequently, the requirement to decrease the concentration of paraquat in water is a worldwide challenge as far as water pollution is concerned.

The removal treatment of paraquat can occur through several processes $^{9}$ such as photodegradation, ${ }^{10}$ chemical degradation, ${ }^{11}$ and microbial metabolism. ${ }^{12}$ First, the photodecomposition reactions occur within a few centimeters of the soil's surface ${ }^{13}$ and depend largely on UV intensity. ${ }^{14}$ Other studies proved that paraquat removal from aqueous solutions could be achieved, especially by adsorption on various porous materials including clays, ${ }^{15-18}$ silica gel, ${ }^{9}$ zeolites, and mesoporous materials. ${ }^{19}$ However, carbonated materials prepared from biomass are the best adsorbent materials that can be used for the treatment of heavy metals and organic pollutants. Predominantly, carbonated materials have been widely studied because they are rich in functional groups $(-\mathrm{OH},-\mathrm{NH}$, and $\mathrm{C}=\mathrm{O}) .^{20,21}$ The high adsorption capacity and efficiency of an adsorbent are mainly controlled by the presence of functional groups in the surface of the adsorbent. ${ }^{22}$

Rahman et al. reported capacity of $99.9 \mathrm{mg} \mathrm{g}^{-1}$ for activated carbon. ${ }^{23} \mathrm{Hsu}$ and Pan utilized modified rice husk and indicated adsorption capacity of $317.7 \mathrm{mg} \mathrm{g}^{-1} .^{24}$ 
The aim of our study is the development of a new low-cost adsorbent from biomass for adsorption applications. Argan nut shell, ${ }^{25}$ wood sawdust, ${ }^{26}$ almond shell, ${ }^{27}$ and lignocellulose biomass are abundant in Morocco, easily available and non-toxic.

The treatment of biomass with acids activates the functional adsorption sites and increases the binding capacity. ${ }^{28}$ This can be achieved in several ways: by reducing the content of cellulose, lignin and hemicelluloses from the solid substrate to be processed as well as by increasing the porosity of or increasing the surface area, which can positively influence adsorption., ${ }^{\mathbf{9} 9}$

To achieve better adsorption of paraquat, in this paper, we investigate the adsorption behavior of paraquat on an adsorbent prepared from jujube seed and the nature and adsorption pathway. The objectives were to determine the adsorption of paraquat including identifying factors controlling its adsorption and a cost analysis of the prepared adsorbent.

\section{Experimental section}

\subsection{Adsorbent preparation}

JS/HSO-700 was prepared by mixing $10 \mathrm{~g}$ of jujube seed grounds with the appropriate quantity of $\mathrm{H}_{2} \mathrm{SO}_{4}$. The mixture was stirred at $40{ }^{\circ} \mathrm{C}$ for 5 hours. Then, the mixture was heated at $700{ }^{\circ} \mathrm{C}$ under $\mathrm{N}_{2}$ atmosphere for 2 hours. The jujube seeds were collected from a mountain in the Taroudant region of Morocco.

\subsection{Characterization methods}

XPS analysis on JS/HSO-700 was carried out using a Thermo Fisher Scientific ESCALAB 250Xi X-ray photoelectron spectroscopy system equipped with $\mathrm{Al} \mathrm{K} \alpha \mathrm{X}$-ray source $(h \nu=1486.7 \mathrm{eV})$ to study the chemical states of synthesized samples.

Thermogravimetry analyses (TGA) were performed to determine the dehydration kinetics of jujube seed. The thermal decomposition of the jujube seed proceeded under air between $25{ }^{\circ} \mathrm{C}$ and $900{ }^{\circ} \mathrm{C}$ with a heating rate of $10{ }^{\circ} \mathrm{C} \min ^{-1}$ (using Shimadzu Instruments DTG-60 equipment).

Scanning electron microscopy (SEM) analyses were used to observe the morphology of jujube seed and JS/HSO-700.

The Brunauer-Emmett-Teller (BET) surface area $\left(S_{\mathrm{BET}}\right)$ of JS/ HSO-700 was determined by the nitrogen adsorption and desorption isotherms; pore size distribution and specific surface area were measured using an AUTOSORB-1 surface area and pore size analyzer at $77 \mathrm{~K}$.

The Fourier transform infrared spectra of jujube seed and JS/ HSO-700 samples were obtained in the mid-infrared region (400-4000 $\mathrm{cm}^{-1}$ ) using Shimadzu $4800 \mathrm{~S}$.

Raman spectroscopy was used to characterize the prepared JS/HSO-700. The equipment used to obtain various vibration spectra was a spectrometer NRS-5100 model Jasco Raman spectrometer using a CCD detector, a laser line of $532 \mathrm{~nm}$ and objective lens $100 \times$, with a laser power of $1.6 \mathrm{~mW}$.

\subsection{Adsorption procedure}

The initial $\mathrm{pH}$ effect testing was carried out by mixing $20 \mathrm{mg}$ of JS/HSO-700 and $100 \mathrm{~mL}$ of paraquat $\left(100 \mathrm{mg} \mathrm{L}^{-1}\right)$; the initial $\mathrm{pH}$ was adjusted using buffer solution (4.0-9.0). The kinetic studies were done with $20 \mathrm{mg}$ of JS/HSO-700 and an initial concentration of $100 \mathrm{mg} \mathrm{L}^{-1}$. A volume of paraquat solution $(100 \mathrm{~mL})$ was agitated $(200 \mathrm{rpm})$ at different temperatures (298, 303, and 313 $\mathrm{K})$ for different contact times (10-180 $\mathrm{min}$ ) and the solution was centrifuged to remove the adsorbent. The residual paraquat concentrations were determined spectrophotometrically. The isotherm studies were carried out by agitating $100 \mathrm{~mL}$ of different concentrations of paraquat $\left(10-100 \mathrm{mg} \mathrm{L}^{-1}\right)$ mixed with $20 \mathrm{mg}$ of JS/HSO-700 at three temperatures $(298,303$, and $313 \mathrm{~K}$ ) and $\mathrm{pH} 6.5$ for $60 \mathrm{~min}$.

\section{Results and discussion}

\subsection{Characterizations of JS/HSO-700}

(a) X-ray photoelectron spectroscopy. XPS of C1s and O1s in Fig. 1 noticeably shows the existence and chemical character of carbon and oxygen in JS/HSO-700. The deconvolution of the C1s spectrum (Fig. 1a) indicates three peaks corresponding to $\mathrm{C}=\mathrm{C}(283.5 \mathrm{eV}), \mathrm{C}-\mathrm{O}(286.2 \mathrm{eV})$ and $\mathrm{C}=\mathrm{O}(288.9 \mathrm{eV})$. Likewise, the deconvolution of the O1s spectrum (Fig. 1b) displays three peaks positioned at 531.5, 533.3, and $535.4 \mathrm{eV}$, which correspond to $\mathrm{C}=\mathrm{O}, \mathrm{C}=\mathrm{O}$, and $\mathrm{C}-\mathrm{OH} .^{27,30}$

(b) Thermogravimetric analysis-TGA. TGA of jujube seeds (Fig. 1c) shows small initial drop in weight from 25 to $100{ }^{\circ} \mathrm{C}$. This initial drop in weight $(9.91 \%)$ is regularly credited to the release of water related to humidity absorbed on the surface. After the initial drop, a sharp decrease in weight occurs until approximately $550{ }^{\circ} \mathrm{C}(88.43 \%)$. This sharp decrease can be associated with the decomposition of the lignocellulosic structure by rupture of its macromolecular chains. ${ }^{31}$ With increasing temperature, a constant stage in TGA curves exists up to the limit of $900{ }^{\circ} \mathrm{C}$ established for the analysis.

(c) FTIR spectra of JS/HSO-700. The spectra of jujube seeds show different peaks corresponding to different functional groups (Fig. 1d). The spectral peaks at $3366 \mathrm{~cm}^{-1}$ correspond to $-\mathrm{OH}$ functional groups. The peaks at 2939 and $2872 \mathrm{~cm}^{-1}$ indicate the presence of $-\mathrm{C}-\mathrm{H}$ stretching in methyl and methylene groups (asymmetric and symmetric stretching). Furthermore, other functional groups present are the ether groups (ROR-) at $1748 \mathrm{~cm}^{-1}$ and the aromatic $\mathrm{C}=\mathrm{C}$ bonds at $1629 \mathrm{~cm}^{-1}$. The peak located at $1530 \mathrm{~cm}^{-1}$ is assigned to the $\mathrm{C}=\mathrm{C}$ ring stretch of aromatic rings. ${ }^{32}$ The band located at $1463 \mathrm{~cm}^{-1}$ confirms the presence of $\mathrm{C}=\mathrm{C}$ of aromatic rings. ${ }^{33}$ The ester group (R-C-O-R-) was observed at $1386 \mathrm{~cm}^{-1}$, with -C-Ostretching at $1100 \mathrm{~cm}^{-1}$. The peak observed at $1245 \mathrm{~cm}^{-1}$ might be assigned to $\mathrm{C}-\mathrm{O}$ stretching vibrations and $-\mathrm{C}=\mathrm{O}$ groups are observed at $1047 \mathrm{~cm}^{-1}$. The IR band located at $572 \mathrm{~cm}^{-1}$ is ascribed to in-plane ring deformation. ${ }^{34}$

The preparation of JS/HSO-700 from jujube seeds by $\mathrm{H}_{2} \mathrm{SO}_{4}$ and thermal treatment at $700{ }^{\circ} \mathrm{C}$ led to decrease in the intensities and shifts of the peaks at 3366, 1629, and $572 \mathrm{~cm}^{-1}$ (Fig. 1d). However, the other peaks disappeared due to the thermal treatment used during the preparation of JS/HSO-700.

(d) Textural characterization of the adsorbents. The adsorption/desorption isotherm of JS/HSO-700 and the corresponding $\mathrm{BJH}$ pore diameter distribution curves are presented in Fig. 1. From Fig. 1e, it can be seen that with the increase in 

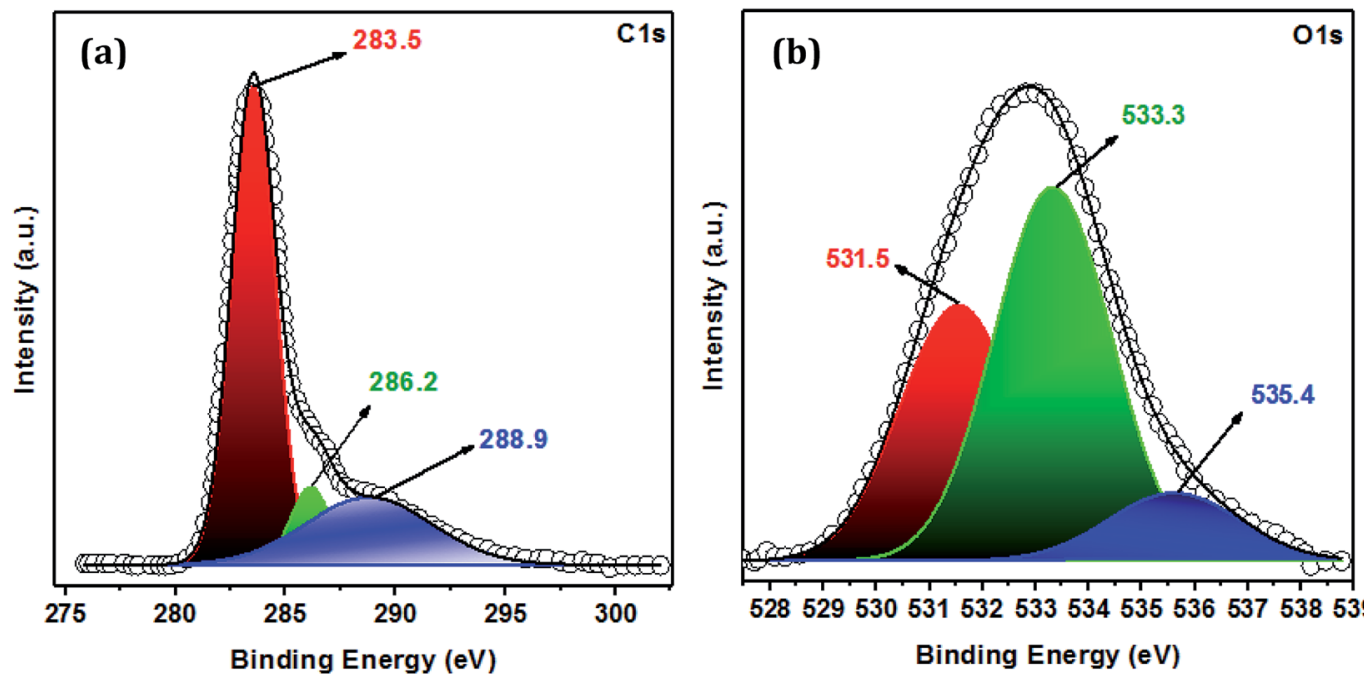

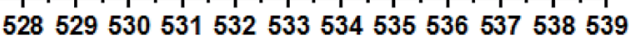
Binding Energy (eV)
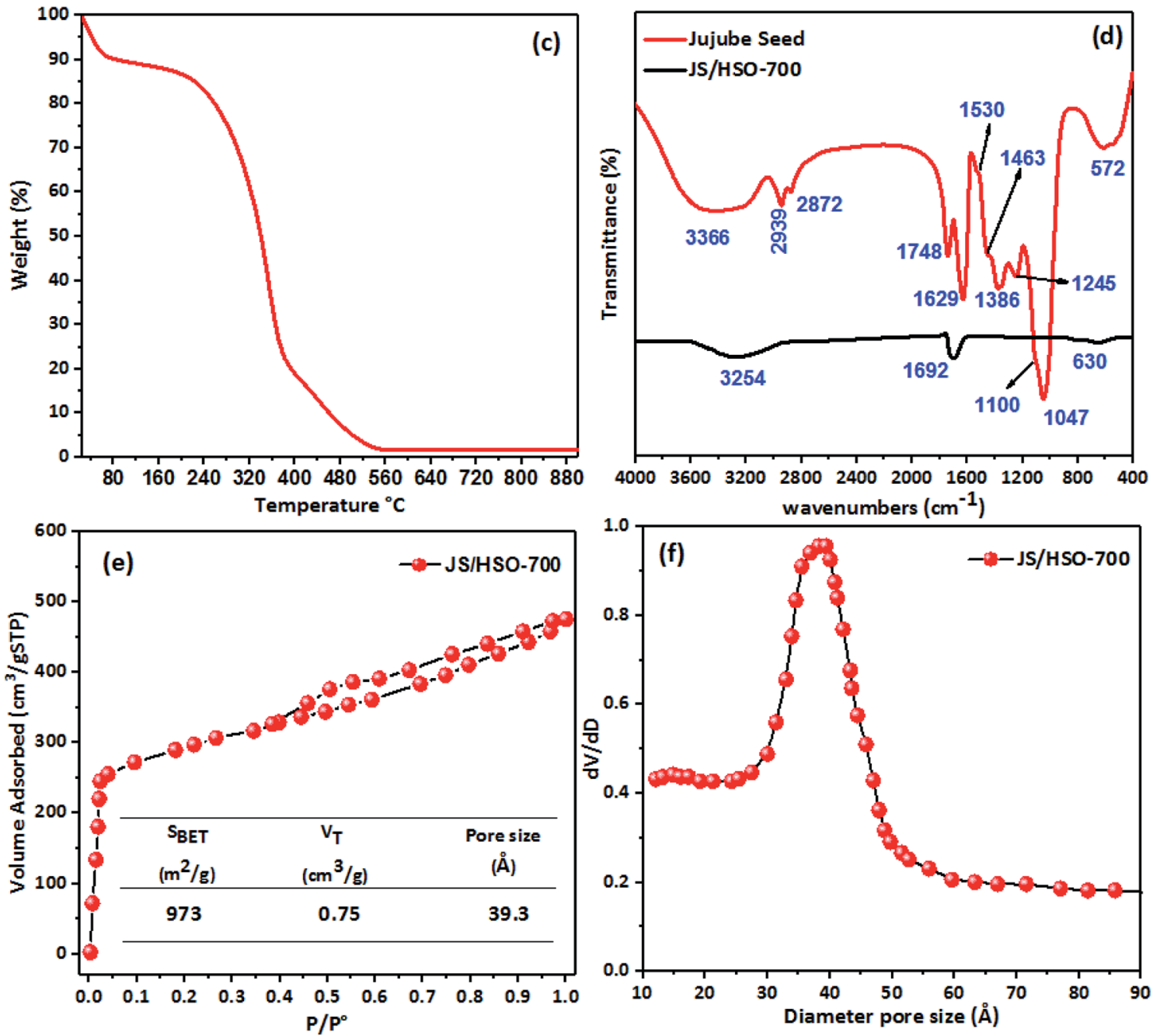

Fig. 1 (a) High-resolution XPS scans of $\mathrm{C}$ 1s, (b) $\mathrm{O}$ 1s of JS/HSO-700 (c) TGA analyses of jujube seed, (d) FTIR spectra of jujube seed and JS/HSO700, (e) nitrogen physisorption of JS/HSO-700, (f) pore size distribution.

pressure, the adsorption amount increases clearly. The isotherms can be assigned to type IV isotherms with H4-type hysteresis loops, suggesting a slit pore structure of JS/HSO700. From Fig. 1e and f, we can infer that JS/HSO-700 reveals a pore size distribution center at $30-50 \AA$; it also presents a large surface area with a BET surface area of $973 \mathrm{~m}^{2} \mathrm{~g}^{-1}$, micropore volume of $0.75 \mathrm{~cm}^{3} \mathrm{~g}^{-1}$, and an average pore size of $39.3 \AA$ A. 
(e) Scanning electron microscopy. Fig. 2 presents the SEM micrographs of jujube seeds and JS/HSO-700. Raw materials showed smooth surface morphology; after treatment with $\mathrm{H}_{2} \mathrm{SO}_{4}$ and thermal treatment at $700{ }^{\circ} \mathrm{C}$ for 2 hours, we observed the formation and the porosity of the surface of JS/HSO-700.

(f) Raman spectroscopy. Raman spectra (Fig. 3) of JS/HSO700 show two typical peaks at $1545 \mathrm{~cm}^{-1}$ and $1347 \mathrm{~cm}^{-1}$; the first peak is assigned to local defects and disordered carbon with $\mathrm{sp}^{3}$ bonding ( $\mathrm{D}$ band) and the second peak corresponds to the stretching mode of an ordered graphitic structure with $\mathrm{sp}^{2}$ hybridization ( $\mathrm{G}$ band).$^{35}$ Moreover, the ratio of the integrated intensity of the $\mathrm{D}$ peak to $\mathrm{G}$ peak $\left(R\right.$-value, $I_{\mathrm{D}} / I_{\mathrm{G}}$ ) can be used to assess the level of disorder in JS/HSO-700. The intensity ratio of the signals, i.e., $I_{\mathrm{D}} / I_{\mathrm{G}}$ for JS/HSO-700 is 1.03 .

\subsection{Influence of $\mathrm{pH}$}

The $\mathrm{pH}$ of a medium can play a major role because it can affect the aqueous chemistry and surface binding sites of the adsorbent. ${ }^{22}$ Adsorption at $\mathrm{pH}$ values higher than 9.0 was not tested because the paraquat molecules degrade due to the cleavage of pyridine rings in a basic medium. ${ }^{36}$ The results show that maximum removal of paraquat onto JS/HSO-700 was observed in the range of $6.5-9.0$ (Fig. 4a). In the acidic range, the percentage of removal decreased probably due to electrostatic repulsion between the positively charged surface of JS/HSO-700 and the positively charged paraquat molecules. ${ }^{22}$ This outcome is consistent with the results reported by Tsai and co-workers. ${ }^{37}$ Hence, pH 6.5 was used for the next adsorption experiments in this study.

\subsection{Effect of contact time}

The effect of temperature $(298,303$, and $313 \mathrm{~K})$ on the adsorption of paraquat onto JS/HSO-700 was assessed at the concentration of $100 \mathrm{mg} \mathrm{L}^{-1}$ at $\mathrm{pH} 6.5$ (Fig. 4b). It was found that $180 \mathrm{~min}$ of contact time at $313 \mathrm{~K}$ was enough to achieve optimal performance, after which the adsorption capacity of JS/HSO-700 reached its maximum (i.e., 97\% removal). In general, the adsorption on JS/HSO-700 is characterized by fast kinetics, and maximum performance is achieved after $20 \mathrm{~min}$ at $313 \mathrm{~K}$.

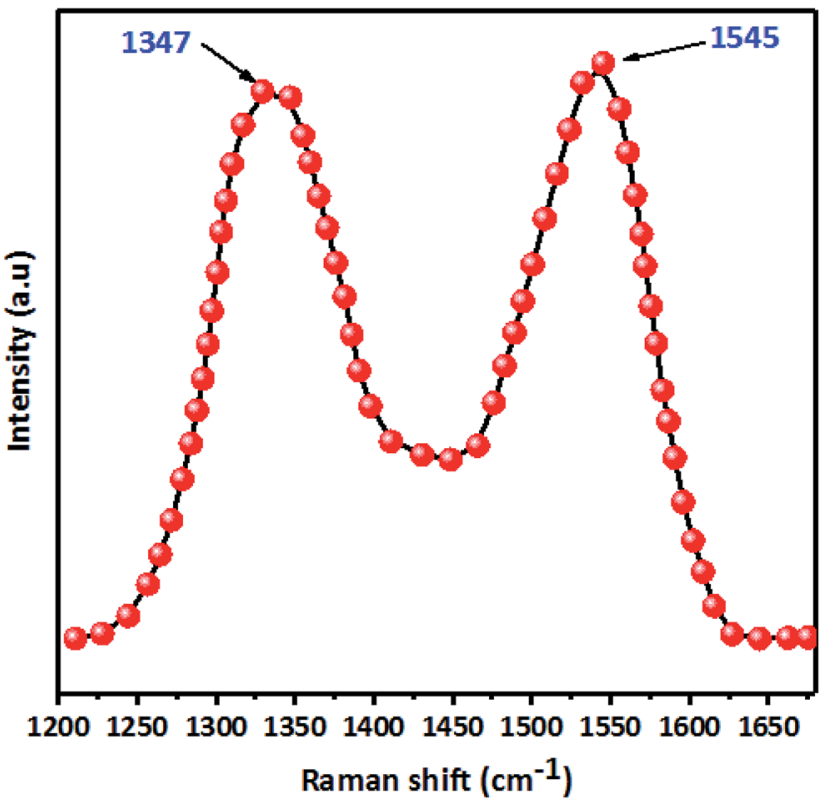

Fig. 3 Raman spectroscopy of JS/HSO-700.

\subsection{Adsorption kinetics}

(a) Pseudo first order and pseudo second-order kinetics. To study the mechanism of paraquat sorption onto JS/HSO-700, several nonlinear kinetic models can be used. In the current study, the experimental results of paraquat sorption onto JS/ HSO-700 were analyzed according to the most frequently used models, i.e., pseudo-first-order (PFO) and pseudo-second-order (PSO) kinetic models presented in Table $1 . .^{38,39}$

To confirm the best model to describe the adsorption kinetics of paraquat sorption onto JS/HSO-700, we compared the values of correlation coefficients and standard error of estimate (SEE), discovering the correlation between experimental data and model-predicted values. The nonlinear plots of paraquat adsorption kinetics and the calculated kinetic parameters are given in Fig. 5 and Table 2, respectively. As can be seen, the correlation coefficients obtained from the PSO model were very close to $1\left(R^{2}=0.999\right)$ compared with $R^{2}$
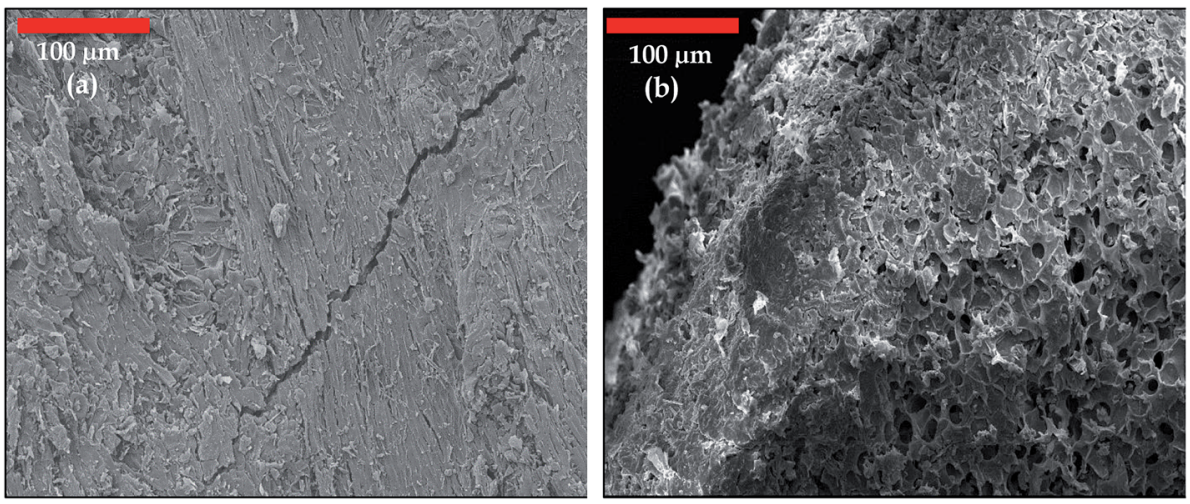

Fig. 2 SEM photographs of (a) jujube seed and (b) JS/HSO-700. 

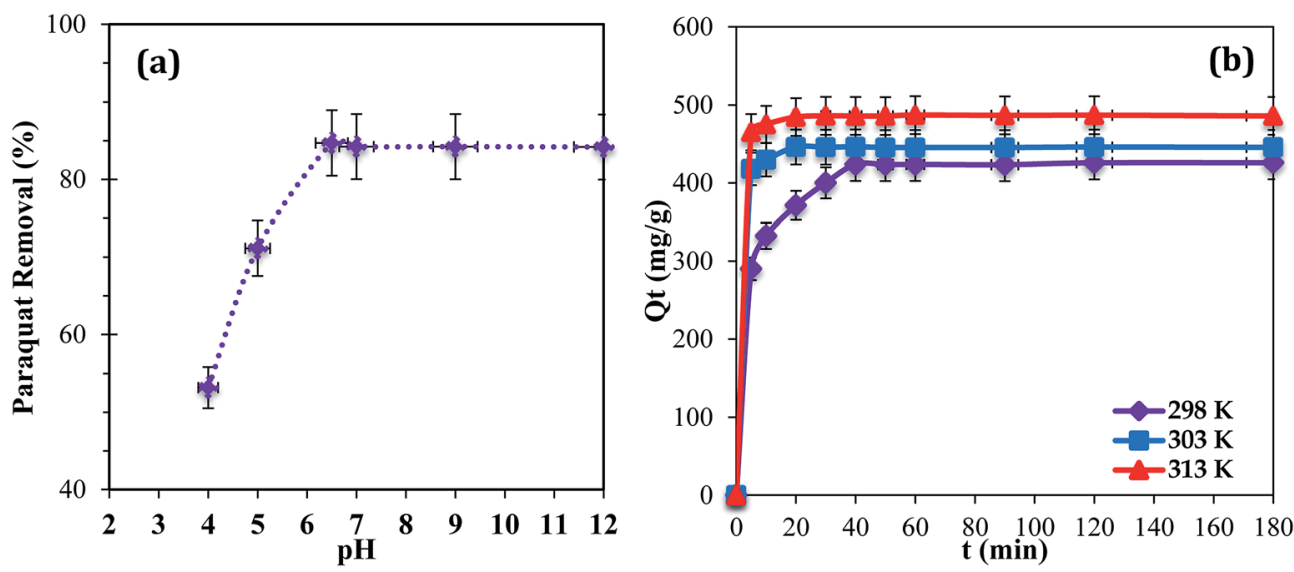

Fig. 4 (a) Effect of initial solution $\mathrm{pH}\left(T=298 \mathrm{~K} ; C_{\mathrm{i}}=100 \mathrm{mg} \mathrm{L}^{-1} ; m=20 \mathrm{mg}\right)$. (b) Effect of contact time (temperature: 298,303 , and $313 \mathrm{~K} ; C_{\mathrm{i}}=$ $\left.100 \mathrm{mg} \mathrm{L}^{-1} ; m=20 \mathrm{mg} ; \mathrm{pH}=6.5\right)$.

Table 1 Nonlinear kinetics, equilibrium adsorption models and thermodynamic equations

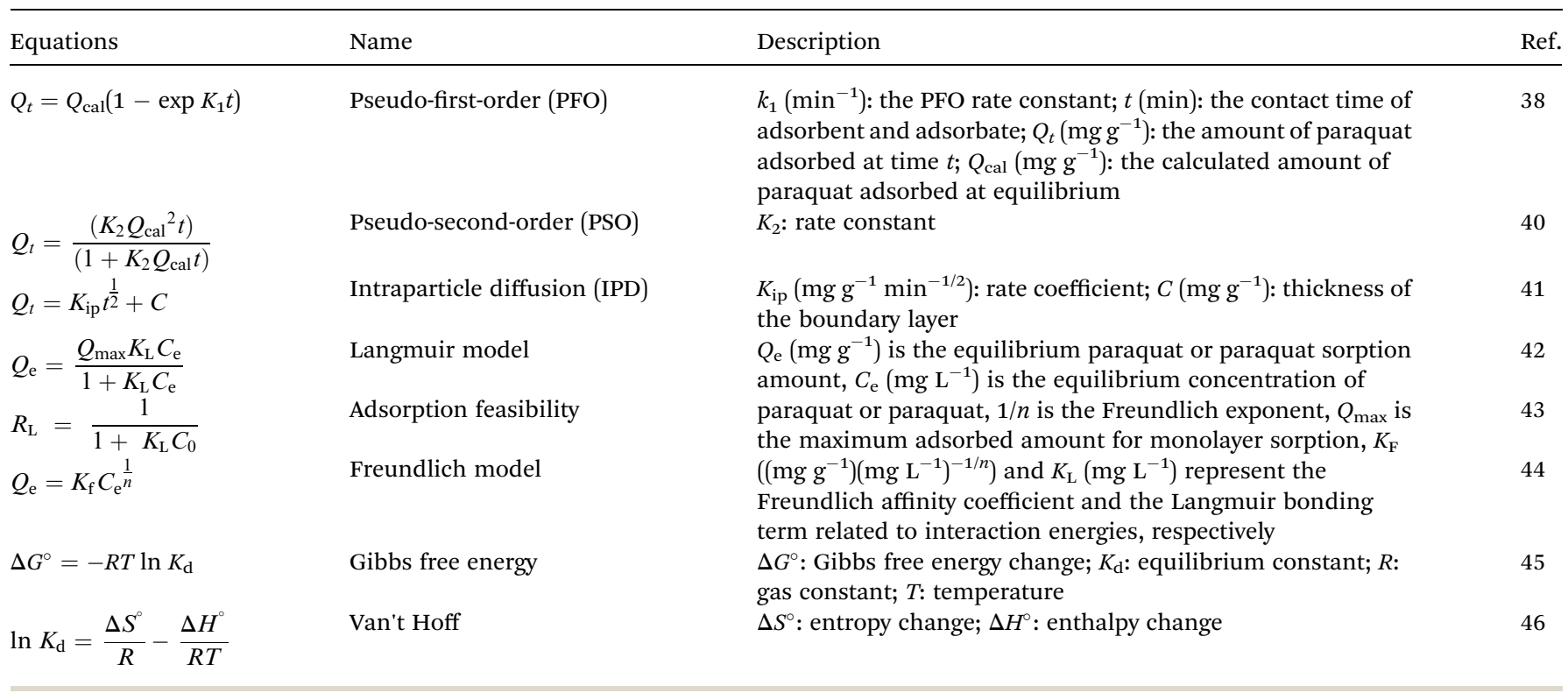

obtained from the PFO model. Furthermore, SEE of the PSO model was the lowest, which was in contrast with that of the PFO model. Consequently, the PSO model fitted the adsorption data of paraquat on JS/HSO-700 at all studied temperatures, which indicated that the rate-controlling process was at least partially a chemically mediated process. ${ }^{47}$

(b) Intra-particle diffusion. To examine the mechanism of paraquat transfer onto the surface of JS/HSO-700, the kinetic results were analyzed using the nonlinear intraparticle diffusion model expressed by the equation presented in Table $1 .^{\mathbf{4 1}}$ The fitting parameters for the intraparticle kinetic model of paraquat adsorption onto JS/HSO-700 at different temperatures are given in Table 2. For all three temperature values, the plotted intra-particle diffusion model did not pass through the origin (Fig. 5); this indicates that intraparticle diffusion of paraquat solution onto $\mathrm{JS} / \mathrm{HSO}-700$ is not the only rate- controlling step. $^{43}$ The $K_{\text {ip }}$ (intra-particle diffusion rate constant) values for paraquat adsorption were calculated to be $23.90,19.45$, and $20.89 \mathrm{mg} \mathrm{g}^{-1} \mathrm{~min}^{-1 / 2}$ at 298,303 , and $313 \mathrm{~K}$, respectively. These outcomes showed that the adsorption of paraquat occurred in two stages: very fast surface adsorption and slow intraparticle diffusion. ${ }^{22}$

\subsection{Adsorption isotherms}

To examine the interaction between paraquat and JS/HSO-700 at equilibrium, the adsorption data were analyzed by nonlinear Langmuir and Freundlich models (Table 1). ${ }^{48,49}$ From Fig. 6 and Table 3, we infer that the nonlinear Langmuir isotherm fits the adsorption equilibrium data well compared to that observed for Freundlich isotherm for all temperature values. These findings indicate the suitability of the Langmuir equation to describe the adsorption of paraquat onto JS/HSO-700, which is explained by 


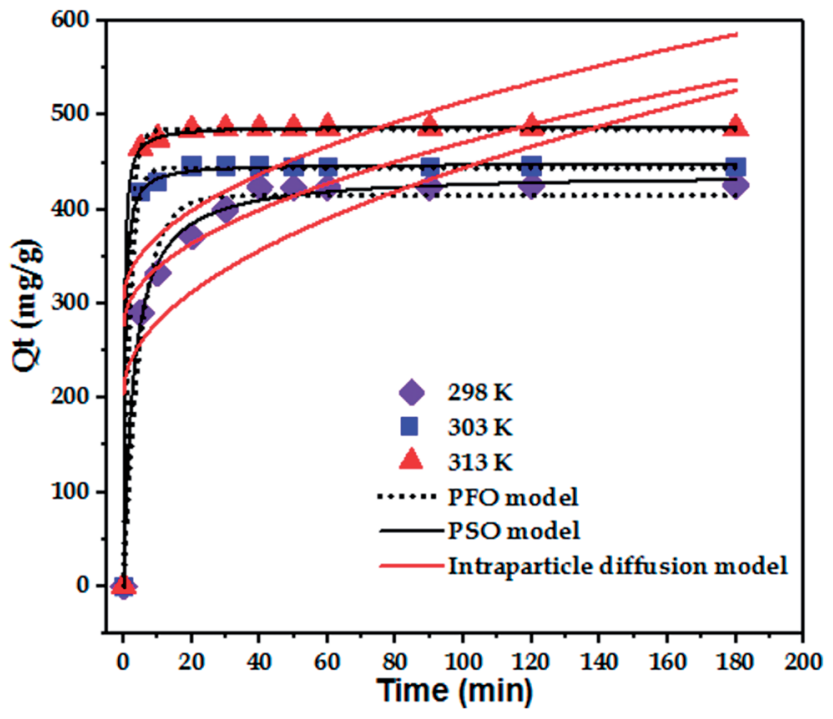

Fig. 5 Nonlinear fit models: PFO, PSO, and IPD.

monolayer adsorption of paraquat and the presence of homogenous active sites on the surface of JS/HSO-700. ${ }^{22,50}$ The obtained adsorption capacity of paraquat onto JS/HSO-700 ranged between $486.70 \pm 4.47$ and $851.20 \pm 13.2 \mathrm{mg} \mathrm{g}^{-1}$. The increase in adsorption capacity $\left(Q_{\max }\right)$ with increasing temperature, as explained by Yuanqing Huang and coworkers, ${ }^{22}$ is because the bond energy between the surface sites of adsorbent and pollutant molecules is larger at higher temperatures and adsorption onto JS/HSO-700 is supported at higher temperatures. Moreover, the adsorption of paraquat onto $\mathrm{JS} / \mathrm{HSO}-700$ is favorable at all studied temperatures with the value of $R_{\mathrm{L}}$ ranging from 0.26 to 0.017 (Table 4). However, the values of $1 / n$ are less than 1 at all the studied temperatures, indicating chemisorption process of paraquat onto JS/HSO-700. ${ }^{51}$

The sorption capacity of paraquat onto JS/HSO-700 was compared with that of other adsorbents reported in the literature for paraquat removal. For example, Hsu et al. ${ }^{24}$ used modified rice husk as an adsorbent for paraquat removal and found adsorption capacity of $317.7 \mathrm{mg} \mathrm{g}^{-1}$. Rongchapo et al. ${ }^{19}$

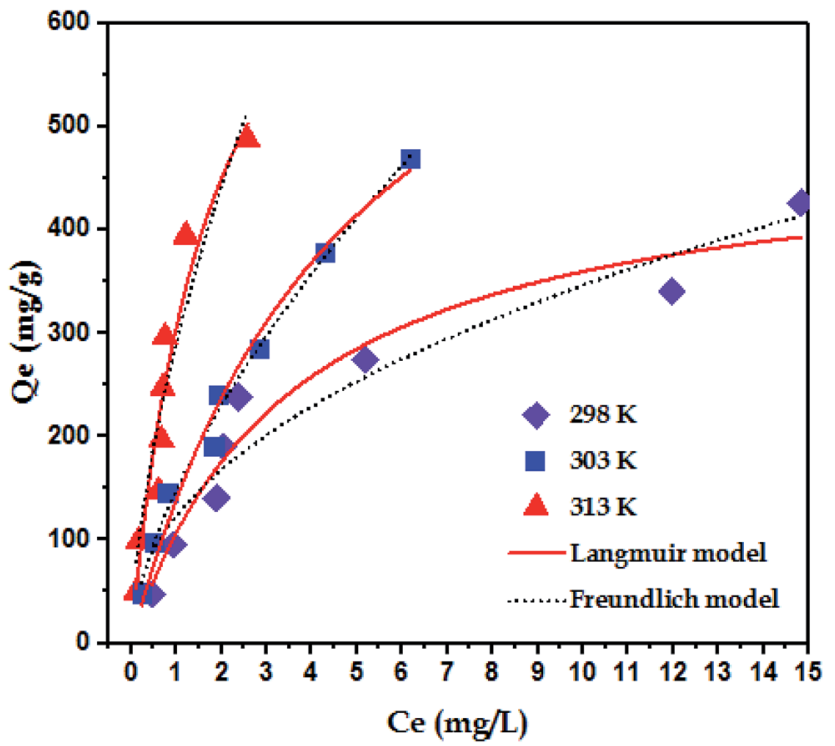

Fig. 6 Nonlinear isotherm models of paraquat adsorbed onto JS/ $\mathrm{HSO}-700$.

reported adsorption capacity of $185.2 \mathrm{mg} \mathrm{g}^{-1}$ using $\mathrm{NaY}$ as an adsorbent. Also, Hamadi et al. ${ }^{52}$ utilized commercial activated carbon and showed adsorption capacity of $75.8 \mathrm{mg} \mathrm{g}^{-1}$. It is clear that the prepared JS/HSO-700 is one of the best-reported adsorbents, and it can be considered a promising alternative adsorbent for paraquat removal.

\subsection{Thermodynamics of adsorption}

A study of the effect of temperature on adsorption of paraquat onto JS/HSO-700 is required. Three temperatures were examined: 298,303 , and $313 \mathrm{~K}$. From our results, it was observed that the solution temperature significantly affects paraquat adsorption onto JS/HSO-700. The thermodynamic parameters such as Gibbs free energy $\left(\Delta G, \mathrm{~kJ} \mathrm{~mol}^{-1}\right)$, enthalpy $\left(\Delta H, \mathrm{~kJ} \mathrm{~mol}^{-1}\right)$ and entropy $\left(\Delta S, \mathrm{~kJ} \mathrm{~mol}^{-1} \mathrm{~K}^{-1}\right)$ were determined using Van't Hoff and Gibbs free energy equations (Table 1$).{ }^{53}$

Table 2 Kinetic model parameters (PFO, PSO, IPD) for paraquat adsorption at various temperatures

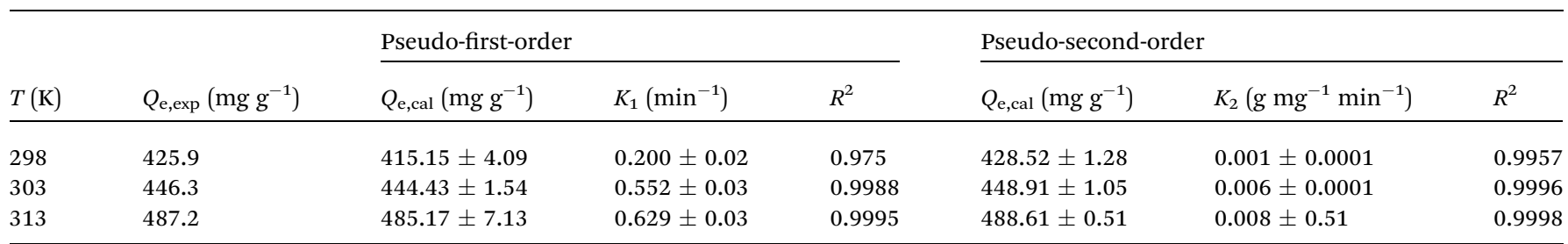

\begin{tabular}{llll}
\hline & Intraparticle diffusion model & & \\
\cline { 2 - 5 }$T(\mathrm{~K})$ & $K_{\text {ip }}\left(\mathrm{mg} \mathrm{g}^{-1} \mathrm{~min}^{-1 / 2}\right)$ & $C_{1}\left(\mathrm{mg} \mathrm{g}^{-1}\right)$ & \\
\hline 298 & $23.90 \pm 7.24$ & $205.32 \pm 53.70$ & $R^{2}$ \\
303 & $19.45 \pm 9.24$ & $276.91 \pm 68.55$ & 0.5476 \\
313 & $20.89 \pm 10.18$ & $305.49 \pm 75.54$ & 0.3297
\end{tabular}


Table 3 Isotherm model parameters for the adsorption of paraquat onto JS/HSO-700 at various temperatures

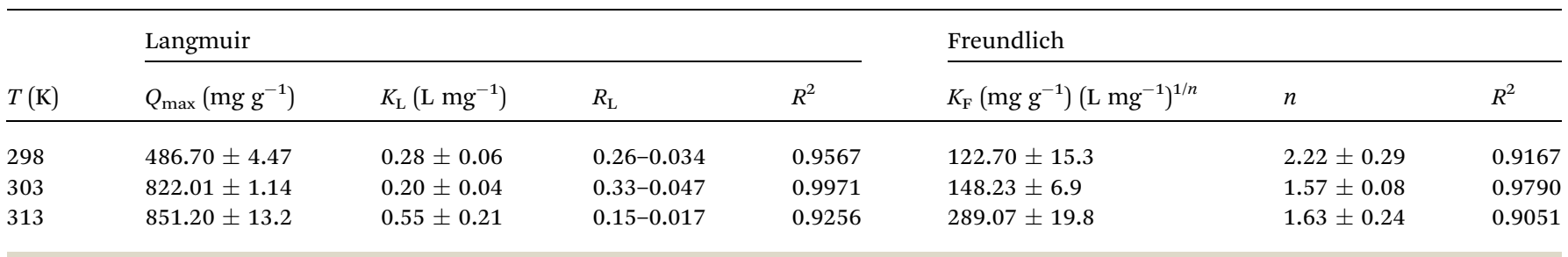

Table 4 Thermodynamic parameters for the adsorption of paraquat onto JS/HSO-700

\begin{tabular}{lllll}
\hline & & \multicolumn{2}{l}{$\Delta G\left(\mathrm{~kJ} \mathrm{~mol}^{-1}\right)$} & \\
\cline { 3 - 5 }$\Delta H\left(\mathrm{~J} \mathrm{~mol}^{-1}\right)$ & $\begin{array}{l}\Delta S \\
\left(\mathrm{~J} \mathrm{~mol}^{-1} \mathrm{~K}^{-1}\right)\end{array}$ & $293 \mathrm{~K}$ & $303 \mathrm{~K}$ & $313 \mathrm{~K}$ \\
\hline 71.301 & 269.647 & 78.935 & 81.632 & 84.328
\end{tabular}

Based on the experimental results displayed in Fig. S1, $\dagger$ we calculated the thermodynamic parameters of paraquat adsorbed onto JS/HSO-700 (Table 4). As shown, the positive values of $\Delta G$ indicate that the process is less spontaneous and the positive values of $\Delta H$ show the need for energy input from the surroundings for the process to occur. Therefore, the sorption of paraquat on JS/HSO-700 is an endothermic process. ${ }^{54}$ The positive value of $\Delta S$ revealed the affinity of JS/HSO-700 for paraquat and increasing randomness at the solid-solution interface during the adsorption. ${ }^{55}$

\subsection{Regeneration}

The regeneration of JS/HSO-700 after paraquat adsorption is conducted by thermal annealing under an $\mathrm{N}_{2}$ atmosphere. From Fig. 7a, we note that the efficacity of JS/HSO-700 decreased by $3.18 \%$ after five cycles. Besides, about $97 \mathrm{wt} \%$ of JS/HSO-700 was recovered.

The decrease in the efficiency of JS/HSO-700 after five cycles is due to the mesopore structure filling mechanism. These
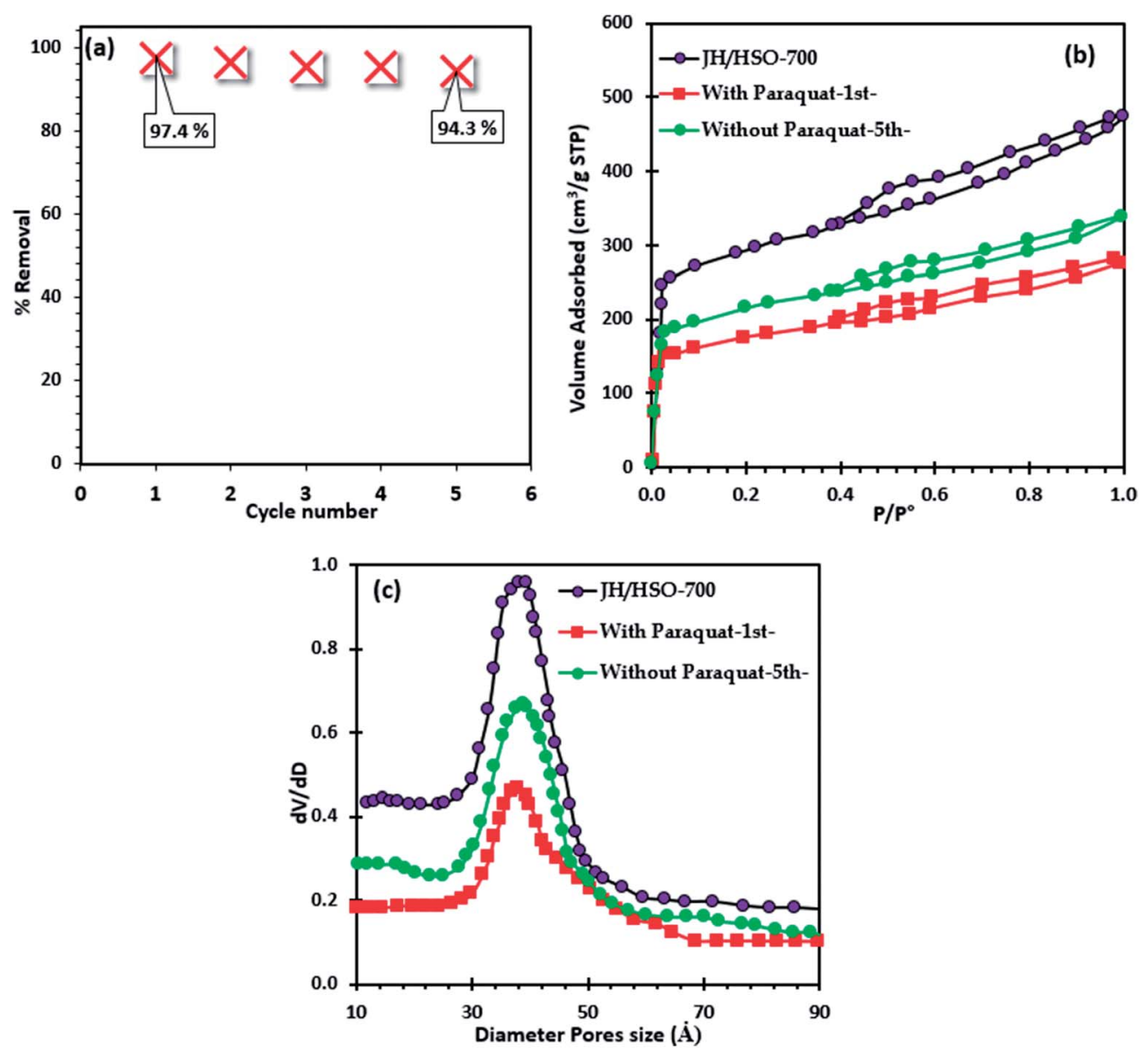

Fig. 7 (a) Regeneration of JS/HSO-700, (b) nitrogen physisorption of JS/HSO-700 after paraquat adsorption and (c) pore size distribution. 

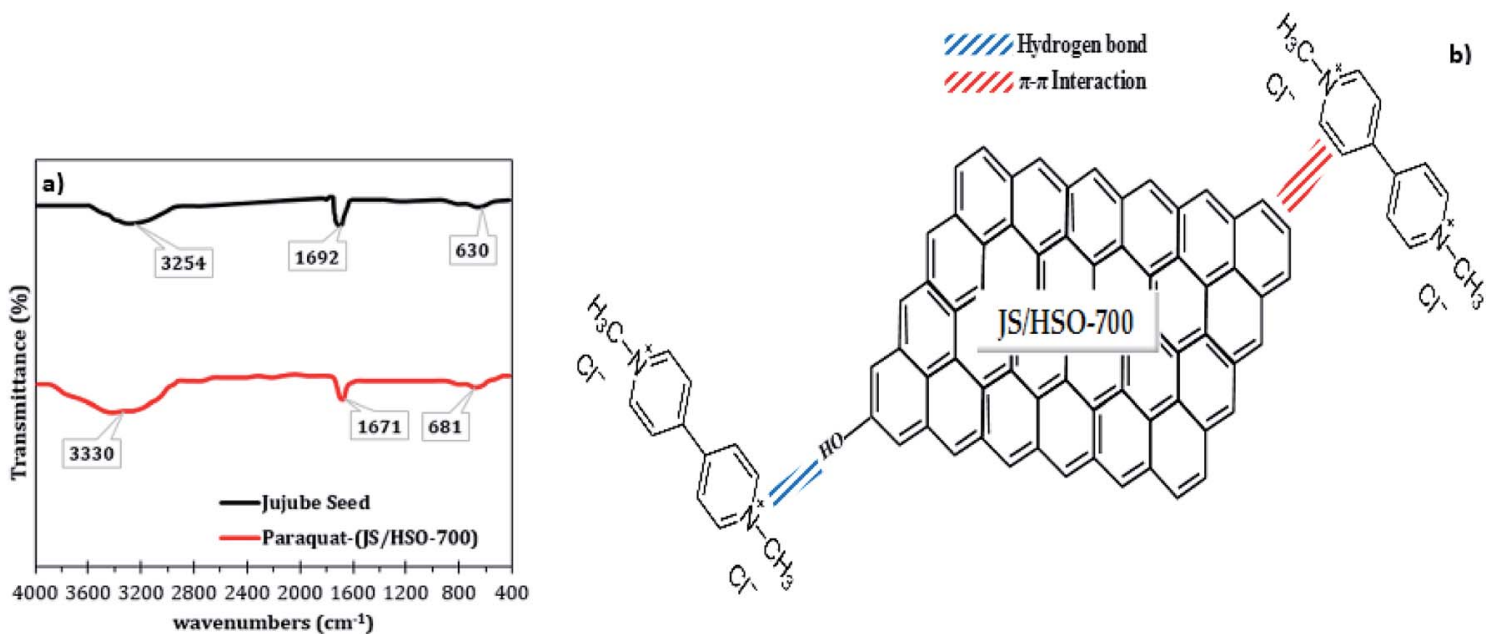

Fig. 8 (a) FTIR spectra of JS/HSO-700 after paraquat adsorption; (b) proposed adsorption mechanism of paraquat onto JS/HSO-700.

results are confirmed by nitrogen physisorption of JS/HSO-700 after adsorption (Fig. 7b), which shows that the surface specific area decreases from 973 to $580 \mathrm{~m}^{2} \mathrm{~g}^{-1}$ and the pore volume decreases from 0.75 to $0.40 \mathrm{~cm}^{3} \mathrm{~g}^{-1}$ (Table S1 $\dagger$ ). The $\mathrm{N}_{2}$ adsorption isotherm of regenerated JS/HSO-700 after five cycles (without paraquat $-5^{\text {th }}$-) is quite similar to that of original JS/ HSO-700. However, there is slight decrease in $S_{\mathrm{BET}}$ and $V_{\mathrm{T}}$ (Table S1 $\dagger$ ), which can be ascribed to the low remaining amount of paraquat molecules on the JS/HSO-700 surface during the regeneration process.

\subsection{Mechanism of paraquat adsorbed onto JS/HSO-700}

The mechanism of paraquat removal was investigated based on FTIR and Raman before and after adsorption (Fig. S2 $\dagger$ and 8a). The FTIR spectra of the prepared JS/HSO-700 show two principal peaks corresponding to $-\mathrm{OH}$ functional groups $\left(3254 \mathrm{~cm}^{-1}\right)$ and aromatic $\mathrm{C}=\mathrm{C}$ bonds $\left(1629 \mathrm{~cm}^{-1}\right)$. However, in FTIR spectra after paraquat adsorption (Fig. 8a), both peaks ascribed to $-\mathrm{OH}$ and $\mathrm{C}=\mathrm{C}$ shift by $+76 \mathrm{~cm}^{-1}$ and $-21 \mathrm{~cm}^{-1}$, which confirms the interaction between these groups and paraquat. Raman spectra (Fig. S2 $\dagger$ ) of JS/HSO-700 after adsorption confirm these interactions. Moreover, the variation of the $I_{\mathrm{D}} / I_{\mathrm{G}}$ ratio from 1.03 to 0.98 shows that two typical peaks of carbon with $\mathrm{sp}^{3}$ bonding and graphitic structure with $\mathrm{sp}^{2}$ hybridization participate in the adsorption mechanism of paraquat.

According to these results, the adsorption mechanism of paraquat onto JS/HSO-700 (Fig. $8 \mathrm{~b}$ ) can be summarized as follows:

(i) The adsorption of paraquat molecule inside the JS/HSO700 adsorbent (pore filling).

(ii) The $\pi-\pi$ interaction between the double bonds of paraquat molecule and those of JS/HSO-700.

(iii) Hydrogen bonding between $\mathrm{OH}$ - groups present on the surface of JS/HSO-700 and the nitrogen atoms present in the structure of paraquat molecule.

\subsection{Optimization of paraquat sorption using the RSM} method: statistical analysis and model interpretation

The procedure of RSM modeling is described in the ESI $\dagger$. Table $\mathrm{S} 3 \dagger$ represents the ANOVA results of paraquat sorption. The model F-value was found to be 23.0493 and the $P$-value less than 0.05 implied that the designed model is significant. ${ }^{56,57} \mathrm{In}$ addition, the results of ANOVA showed that the lack-of-fit was not significant; this indicates that the phenomenon was explained very well by our model with a confidence level of 95\%. ${ }^{26,58}$ According to the values of the determination coefficients $R^{2}=0.956\left(R_{\mathrm{dj}}{ }^{2}=0.914\right)$, we can conclude that there is good agreement between the experimental and predicted responses of paraquat removal onto JS/HSO-700. ${ }^{59,60}$ In the same context, Fig. 9a shows homogenous distribution of residues on the "0" axis, ${ }^{61}$ which confirms the normality of the residues and the absence of outliers. In Fig. 9b, the experimental paraquat removal (\%) values are very well aligned with the Henry line. ${ }^{62}$ The significance of each coefficient was determined by $P$-values (Table $3 S^{\dagger} \dagger$ ) and insignificant terms were eliminated from the model. ${ }^{59,61-64}$ Based on these results, the second-order polynomial for paraquat removal is expressed as follows:

$$
\begin{aligned}
& R \% \text { (paraquat) }=82.025+4.798 X_{\mathrm{CT}}+3.387 X_{\mathrm{T}}+2.104 X_{\mathrm{IC}} \\
&+5.905 X_{\mathrm{pH}}-2.142 X_{\mathrm{CT}}{ }^{2}-1.278 X_{\mathrm{pH}}{ }^{2}-2.346 X_{\mathrm{CT}-\mathrm{T}}
\end{aligned}
$$

Here, $X_{\mathrm{CT}}$ is the contact time $(\mathrm{min}), X_{\mathrm{T}}$ is the temperature $(\mathrm{K})$, $X_{\mathrm{IC}}$ is the initial concentration $\left(\mathrm{mg} \mathrm{L}^{-1}\right)$ and $X_{\mathrm{pH}}$ is the $\mathrm{pH}$.

To explain the possible interactions between different parameters and their influences on the adsorption process, CDD is the perfect solution..$^{65}$ We used 3D and 2D presentation RSM (Fig. 9c) for the optimization of paraquat sorption, and two variables were taken into consideration at a time ${ }^{66,67}$ From the results of these presentations, we infer that the increase in the $\mathrm{pH}$ values from 4 to 6.5 increases the paraquat removal (\%) significantly from 60.20 to $85 \%$. In addition, the increase in contact time favored the increase in paraquat removal from $85 \%$ to $94.4 \%$. Based on RSM presentation, the optimum 


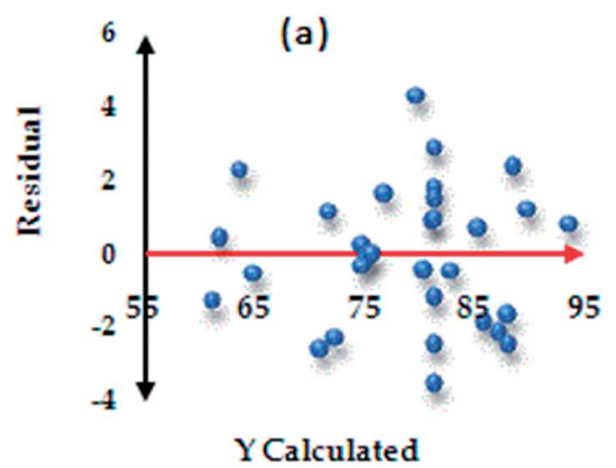

(c)

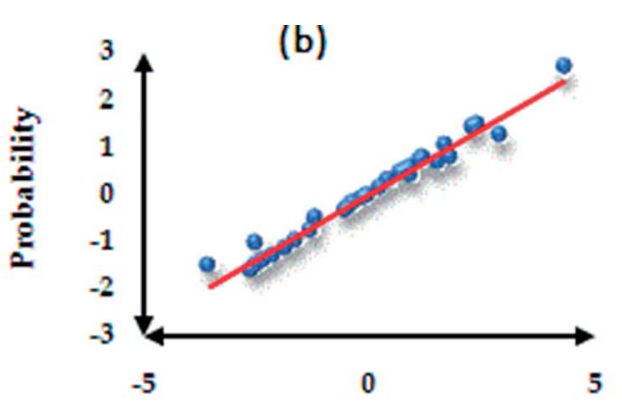

Residual

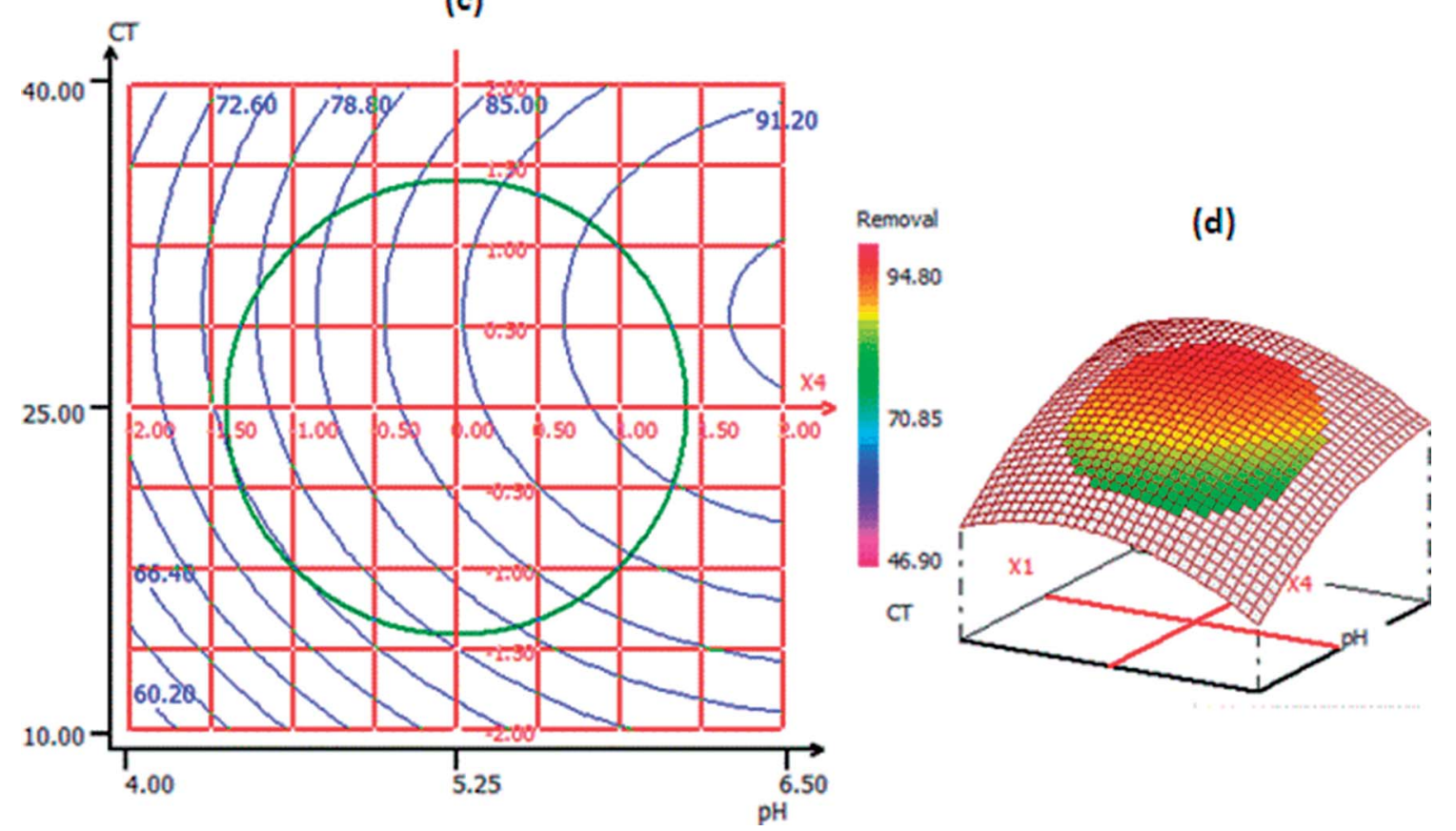

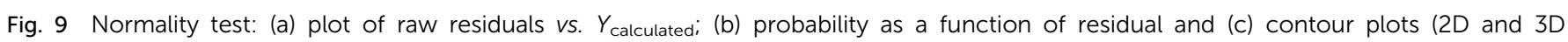
presentations).

conditions for the highest removal yield of paraquat were found: $\mathrm{pH}=6.49, \mathrm{CT}=25.88 \mathrm{~min}, T=308 \mathrm{~K}$ and $\mathrm{IC}=$ $87.50 \mathrm{mg} \mathrm{L}^{-1}$. In these new conditions, the experimental paraquat removal efficiency was found to be $96.7 \pm 2.02 \%$, whereas the value predicted by model was $94.31 \pm 4.43 \%$. Both values are practically identical, which shows that the modelpredicted values are in very good agreement with the experimentally determined values.

\subsection{Cost analysis: JS/HSO-700 as a low-cost adsorbent}

The estimated cost of the process based on experimental results of paraquat adsorption onto JS/HSO-700 is very important for its practical applications including the estimated cost of energy consumption as well as the cost of reagents (sulfuric acid). The following equation was used to assess the cost of the current process: ${ }^{\mathbf{6 8 , 6 9}}$

$$
\text { Operating cost }=C_{\text {energy }}+\sum C_{\text {reagents }}
$$

The operational cost is usually represented in US\$ per $\mathrm{m}^{3}$ or US\$ per kg of pollutants. $C_{\text {energy }}$ in our case represents the energy consumption of the furnace and oven in $\mathrm{USS}^{70}$ and $C_{\text {reagents }}$ is the cost of the reagents used in US\$. From RSMCDD analysis, the optimum conditions for paraquat removal onto JS/HSO-700 are found to be JS/HSO-700 dose $=$ $20 \mathrm{mg}$, volume $=100 \mathrm{~mL}, \mathrm{pH}=6.49, \mathrm{CT}=25.88 \mathrm{~min}, T=308$ $\mathrm{K}$ and $\mathrm{IC}=87.50 \mathrm{mg} \mathrm{L}^{-1}$. Therefore, the operating cost for paraquat removal at these optimum operating conditions was calculated as 11.9 US\$ per $\mathrm{m}^{3}$, which revealed that this adsorption process can be effectively used for the removal of paraquat onto our absorbent. Additionally, the analysis revealed that the cost of electricity was very minor as compared to that of the chemical treatment with sulfuric acid (Fig. 10). 


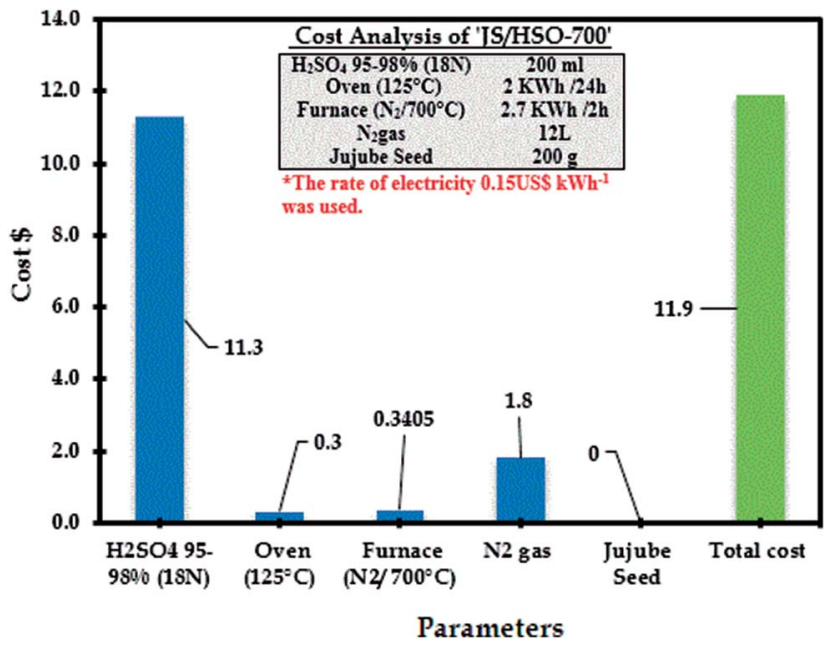

Fig. 10 The operating costs.

\section{Conclusion}

This present study reports the remarkable potential of jujube seeds as an outstanding and low-cost precursor for carbonated adsorbent. A cost analysis performed by our team provides proof of the low operating cost using this eco-friendly material. JS/HSO-700 presents a large surface area with a BET surface area of $973 \mathrm{~m}^{2} \mathrm{~g}^{-1}$, micropore volume of $0.75 \mathrm{~cm}^{3} \mathrm{~g}^{-1}$, and an average pore size of $39.3 \AA$ A. These parameters decreased after adsorption of paraquat, suggesting a mesopore filling mechanism along with the deposition of some functional groups of paraquat on the JS/HSO-700 surface. The adsorption results were better described by the pseudo-second-order kinetic model. Langmuir isotherm model best fitted the adsorption equilibrium data, giving maximum adsorption capacities $\left(Q_{\mathrm{m}}\right)$ of $526.3,625$, and $714 \mathrm{mg} \mathrm{g}^{-1}$ at 298, 303, and $313 \mathrm{~K}$, respectively. The adsorption mechanism was proposed based on solution pH, Raman, FTIR, and BET analyses after adsorption. We concluded that electrostatic interactions between paraquat and JS/HSO-700 adsorbent, $\pi-\pi$ interactions, and hydrogen bonding are the main possible phenomena to describe this mechanism. Finally, these parameters were optimized by the RSM-CCD method.

\section{Conflicts of interest}

Authors declare that they have no conflict of interest.

\section{Acknowledgements}

This work was supported by the University of Ibn Zohr Faculty of Sciences.

\section{References}

1 C. Steven and W. Lenhart, Health Hazard Evaluation Report 94-0413-2560 U.S. Department of Agriculture Animal and
Plant Health Inspection Service Plant Protection and Quarantine, Fayetteville, North Carolina, 1996.

2 L. A. Summers, in Advances in Pesticide Science, ed. H. Geissbühler, P. C. Kearney and G. T. Brooks, Pergamon, 1979, p. II-13.

3 R. Macholz, Nahrung, 1985, 29, 1020.

4 U. S. EPA, Exposure Factors Handbook (Final Report, 1997), U.S. Environmental Protection Agency, Washington, DC, EPA/600/P-95/002F a-c, 1216 pages, 1997.

5 D. C. Ricketts, Pestic. Sci., 1999, 55, 596-598.

6 D. Ait Sidhoum, M. M. Socías-Viciana, M. D. Ureña-Amate, A. Derdour, E. González-Pradas and N. DebbaghBoutarbouch, Appl. Clay Sci., 2013, 83-84, 441-448.

7 H. Nur, A. F. N. A. Manan, L. K. Wei, M. N. M. Muhid and H. Hamdan, J. Hazard. Mater., 2005, 117, 35-40.

8 Z. Mojović, P. Banković, A. Milutinović-Nikolić, J. Dostanić, N. Jović-Jovičić and D. Jovanović, Chem. Eng. J., 2009, 154, 149-155.

9 K. Mahmoudi, K. Hosni, N. Hamdi and E. Srasra, Korean J. Chem. Eng., 2015, 32, 274-283.

10 W. Rongchapo, P. Khamdahsag, N. Grisdanurak, S. Prayoonpokarach and J. Wittayakun, Suranaree J. Sci. Technol., 2016, 23, 343-350.

11 W. Amondham, P. Parkpian, C. Polprasert, R. D. Delaune and A. Jugsujinda, J. Environ. Sci. Health, Part B, 2006, 41, 485-507.

12 B. Singh and K. Singh, Crit. Rev. Microbiol., 2016, 42, 245261.

13 V. R. Hebert and G. C. Miller, J. Agric. Food Chem., 1990, 38, 913-918.

14 D. Janke, J. Basic Microbiol., 1989, 29, 718.

15 M. A. Constenla, D. Riley, S. H. Kennedy, C. E. Rojas, L. E. Mora and J. E. B. Stevens, J. Agric. Food Chem., 1990, 38, 1985-1988.

16 D. R. Narine and R. D. Guy, Soil Sci., 1982, 6, 133.

17 P. Mac Carthy and K. E. Djebbar, J. Environ. Qual., 1986, 15, 103-107.

18 G. Rytwo, S. Nir and L. Margulies, Soil Sci. Soc. Am. J., 1996, 60, 601-610.

19 W. Rongchapo, O. Sophiphun, K. Rintramee, S. Prayoonpokarach and J. Wittayakun, Water Sci. Technol., 2013, 68, 863-869.

20 C. Yan, Y. Chunping, H. Huijun, Z. Guangming, Z. Kun and Y. Zhou, J. Environ. Eng., 2016, 142, C4015001.

21 H. J. He, Z. H. Xiang, X. J. Chen, H. Chen, H. Huang, M. Wen and C. P. Yang, Int. J. Environ. Sci. Technol., 2018, 15, 14911500.

22 Y. Huang, C. Yang, Z. Sun, G. Zeng and H. He, RSC Adv., 2015, 5, 11475-11484.

23 M. M. Rahman, M. Bintey Shajahan, M. Awang, K. Yunus and T. A. Razak, in Advances in Materials and Processing Technologies XV, Trans Tech Publications, 2014, vol. 773, pp. 471-477.

24 S.-T. Hsu and T.-C. Pan, Bioresour. Technol., 2007, 98, 36173621. 
25 M. Zbair, K. Ainassaari, A. Drif, S. Ojala, M. Bottlinger, M. Pirilä, R. L. Keiski, M. Bensitel and R. Brahmi, Environ. Sci. Pollut. Res., 2018, 25, 1869-1882.

26 M. Zbair, Z. Anfar, H. Khallok, H. A. Ahsaine, M. Ezahri and N. Elalem, Fullerenes, Nanotubes, Carbon Nanostruct., 2018, 26, 433-442.

27 H. Ait Ahsaine, M. Zbair, Z. Anfar, Y. Naciri, R. El haouti, N. El Alem and M. Ezahri, Mater Today Chem., 2018, 8, 1-12. 28 I. Anastopoulos, A. Bhatnagar, B. Hameed, Y. S. Ok and M. Omirou, J. Mol. Liq., 2017, 240, 179-188.

29 I. Anastopoulos, I. Margiotoudis and I. Massas, Int. J. Phytoremediation, 2018, 20, 831-838.

30 P. Fu, L. Zhou, L. Sun, B. Huang and Y. Yuan, RSC Adv., 2017, 7, 13383-13389.

31 B. Wielage, T. Lampke, G. Marx, K. Nestler and D. Starke, Thermochim. Acta, 1999, 337, 169-177.

32 C. Bouchelta, M. S. Medjram, O. Bertrand and J.-P. Bellat, J. Anal. Appl. Pyrolysis, 2008, 82, 70-77.

33 H. Deng, G. Li, H. Yang, J. Tang and J. Tang, Chem. Eng. J., 2010, 163, 373-381.

34 Y. Ji, T. Li, L. Zhu, X. Wang and Q. Lin, Appl. Surf. Sci., 2007, 254, 506-512.

35 F. Cesano, D. Scarano, S. Bertarione, F. Bonino, A. Damin, S. Bordiga, C. Prestipino, C. Lamberti and A. Zecchina, J. Photochem. Photobiol., A, 2008, 196, 143-153.

36 J. Weißmüller, Angew. Chem., 1990, 102, 236-237.

37 W. T. Tsai and H. R. Chen, Int. J. Environ. Sci. Technol., 2013, 10, 1349-1356.

38 S. Lagergren, K. Sven. Vetenskapsakad. Handl., 1898, 24, 1.

39 Y. Liu, Colloids Surf., A, 2008, 320, 275-278.

40 G. Mckay, Process Biochem., 1999, 34, 451.

41 W. J. Weber and J. C. Morris, J. Sanit. Eng. Div., Am. Soc. Civ. Eng., 1963, 89, 31-60.

42 I. Langmuir, J. Am. Chem. Soc., 1916, 38, 2221-2295.

43 S. Fan, Y. Wang, Z. Wang, J. Tang, J. Tang and X. Li, J. Environ. Chem. Eng., 2017, 5, 601-611.

44 H. Freundlich, Z. Phys. Chem, 1906, 57, 385.

45 W. Tsai and C. Chang, J. Environ. Sci. Health, Part A: Environ. Sci. Eng., 1995, 30, 525-535.

46 B. H. Hameed, A. A. Ahmad and N. Aziz, Chem. Eng. J., 2007, 133, 195-203.
47 Q. Chai, L. Lu, Y. Lin, X. Ji, C. Yang, S. He and D. Zhang, Environ. Sci. Pollut. Res., 2018, 25, 18443-18450.

48 H. Freundlich, Z. Phys. Chem, 1906, 57A, 385.

49 I. Langmuir, J. Am. Chem. Soc., 1916, 252, 2221-2295.

50 M. Jabli, E. Gamha, N. Sebeia and M. Hamdaoui, J. Mol. Liq., 2017, 240, 35-44.

51 K. Y. Foo and B. H. Hameed, Chem. Eng. J., 2010, 156, 2-10. 52 N. K. Hamadi, S. Swaminathan and X. D. Chen, J. Hazard. Mater., 2004, 112, 133-141.

53 X. Han, W. Wang and X. Ma, Chem. Eng. J., 2011, 171, 1-8.

54 G. A. Adebisi, Z. Z. Chowdhury and P. A. Alaba, J. Cleaner Prod., 2017, 148, 958-968.

55 H. M. F. Freundlich, J. Phys. Chem., 1906, 57, 385-471.

56 Z. Anfar, M. Zbair, H. A. Ahsaine, M. Ezahri and N. El Alem, Fullerenes, Nanotubes, Carbon Nanostruct., 2018, 26, 389-397.

57 M. Zbair, Z. Anfar, H. A. Ahsaine, N. El Alem and M. Ezahri, J. Environ. Manage., 2018, 206, 383-397.

58 M. Zbair, K. Ainassaari, Z. El Assal, S. Ojala, N. El Ouahedy, R. L. Keiski, M. Bensitel and R. Brahmi, Environ. Sci. Pollut. Res., 2018, 25, 35657-35671.

59 M. K. Satapathy and P. Das, J. Environ. Chem. Eng., 2014, 2, 708-714.

60 M. Zbair, H. A. Ahsaine and Z. Anfar, J. Cleaner Prod., 2018, 202, 571-581.

61 S. Dashamiri, M. Ghaedi, A. Asfaram, F. Zare and S. Wang, Ultrason. Sonochem., 2017, 34, 343-353.

62 M. T. Tanyildizi, Chem. Eng. J., 2011, 168, 1234-1240.

63 U. Guyo, T. Makawa, M. Moyo, T. Nharingo, B. C. Nyamunda and T. Mugadza, J. Environ. Chem. Eng., 2015, 3, 2472-2483.

64 Y. Ding and M. Sartaj, J. Environ. Chem. Eng., 2015, 3, 807814.

65 T. A. Saleh, A. Sari and M. Tuzen, J. Environ. Chem. Eng., 2017, 5, 1079-1088.

66 I. A. Bhatti, N. Ahmad, N. Iqbal, M. Zahid and M. Iqbal, J. Environ. Chem. Eng., 2017, 5, 2740-2751.

67 M. Rahimdokht, E. Pajootan and M. Arami, J. Environ. Chem. Eng., 2016, 4, 1407-1416.

68 A. Dalvand, M. Gholami, A. Joneidi and N. M. Mahmoodi, Clean: Soil, Air, Water, 2011, 39, 665-672.

69 D. A. M. Saad and H. Tahir, Ultrason. Sonochem., 2017, 38, 197-213.

70 O. S. Bello, S. Afr. J. Chem., 2013, 66, 32-41. 